OPEN ACCESS

Edited by:

Guigen Li,

Texas Tech University, United States

Reviewed by:

Jianke Sun,

Beijing Institute of Technology, China

Hugo Cruz,

Universidade NOVA de Lisboa,

Portugal

*Correspondence: Filip Bureš

filip.bures@upce.cz Petr Mazúr

Petr.Mazur@vscht.cz

Specialty section:

This article was submitted to

Organic Chemistry,

a section of the journal

Frontiers in Chemistry

Received: 20 November 2020 Accepted: 21 December 2020

Published: 27 January 2021

Citation:

Burešová Z, Klikar M, Mazúr $P$, Mikešová $M$, Kvičala J, Bystron $T$ and Bureš F (2021) Redox Property Tuning in Bipyridinium Salts.

Front. Chem. 8:631477.

doi: 10.3389/fchem.2020.631477

\section{Redox Property Tuning in Bipyridinium Salts}

\author{
Zuzana Burešová ${ }^{1}$, Milan Klikar $^{1}$, Petr Mazúr ${ }^{2 *}$, Michaela Mikešová ${ }^{2}$, Jaroslav Kvičala $^{3}$, \\ Tomas Bystron ${ }^{4}$ and Filip Bures ${ }^{1 *}$ \\ ${ }^{1}$ Institute of Organic Chemistry and Technology, Faculty of Chemical Technology, University of Pardubice, Pardubice, Czechia, \\ ${ }^{2}$ Department of Chemical Engineering, Faculty of Chemical Engineering, University of Chemistry and Technology Prague, Prague, \\ Czechia, ${ }^{3}$ Department of Organic Chemistry, Faculty of Chemical Technology, University of Chemistry and Technology Prague, \\ Prague, Czechia, ${ }^{4}$ Department of Inorganic Technology, Faculty of Chemical Technology, University of Chemistry and Technology \\ Prague, Prague, Czechia
}

Bipyridinium salts are currently very popular due to their perspective applications in redox flow batteries. Hence, we designed and prepared a series of bipyridiniums based on 2,2' -, 3,3'-, and 4,4'-bipyridine and 2,2'-bipyrimidine. The straightforward synthesis utilizes commercially or readily available starting compounds and their direct $\mathrm{N}$-alkylation, mostly using 1,3-propanesultone. All eleven target derivatives with systematically evolved structure were investigated by cyclic voltammetry, which allowed elucidating thorough structure-property relationships. The electrochemical behavior depends primarily on the parent scaffold, type of $\mathrm{N}$-alkylation, number of quaternized nitrogen atoms, planarity, counter ion as well as the used media. Two derivatives featuring quasi-reversible redox processes were further tested on rotating disc electrode and in a flow battery half-cell. 4,4' Bipyridinium derivative bearing two sultone residues showed better performance and stability in the flow half-cell with small capacity decays of $0.09 / 0.15 \%$ per reductionoxidation cycle, based on the number of the utilized redox processes (one/two).

Keywords: bipyridine, bipyridinium, redox flow battery, property tuning, synthesis, electrochemistry

\section{INTRODUCTION}

Bipyridines represent simple yet very interesting and tempting heteroaromatic scaffold with tremendous use across various research fields. In principle, we can distinguish six bipyridine derivatives that differ in the mutual orientation of both pyridine rings. The synthesis of parent bipyridines is well-known since 1950 (Summers, 1984). Some bipyridines occur naturally, for instance $2,2^{\prime}$-bipyridine is present in the petroleum or 2,3' -bipyridine can be found in the seedlings of tobacco (Nicotiana species) (Kallianos et al., 1972; Gray et al., 2008). Relatively small changes in mutual orientation of both bipyridine nitrogen atoms lead to significant structural differences. For instance, X-ray diffraction analysis revealed that both rings in 2,2'-bipyridine are coplanar with the nitrogen atoms in an anti-position. Accordingly, 4,4'-bipyridinium dication possesses planar arrangement (Summers, 1984). Bipyridine salts based mainly on viologen ( $N, N^{\prime}$-dialkyl-4,4'bipyridinium) found manifold applications as active components in electrochromic devices (Monk et al., 1999; Alesanco et al., 2016), molecular machines (Coumans et al., 2013; Song et al., 2017), and redox-flow batteries (Beh et al., 2017; Hu et al., 2017). Recently, redox-flow batteries have gained significant attention due to their perspective to become low-cost energy storage device for large-scale applications. Especially methyl viologen (also known as herbicide paraquat) is used as popular anolyte in aqueous redox-flow batteries (Hu et al., 2017; Janoschka et al., 2016; Liu et al., 2016; Hu et al., 2018; Janoschka et al., 2015), which is mostly due to its well-defined 
electrochemical properties, relatively high solubility, and simple preparation. Divalent bipyridine cation may undergo a two-step reduction to the neutral molecule via a monovalent radical cation, which is often accompanied by a characteristic color change. Moreover, the redox potential and solubility of bipyridines can further be tuned by proper $\mathrm{N}$-substitution and positioning of the nitrogen atoms. Viologen solubility issues can be solved by introduction of solubilizing groups such as 3(trimethylammonium)propyl, 3-sulfonatopropyl, hydroxyalkyl or 3-phosphoniumpropyl, which also improves battery voltage and energy density (DeBruler et al., 2017; Jin et al., 2020; Liu et al., 2020). It is also believed that such structural tuning suppresses eventual dimerization of the reduced form (Hu et al., 2018). Viologen molecular assemblies with up to 15 viologen units were recently tested in RFB providing multi-electron transfer but also significant stability issues (Ohira et al., 2020).

Hence, we report herein on structural elaboration of bipyridine derivatives especially in view of tuning their electrochemical behavior. To the best of our knowledge, no such systematic study on bipyridinium salts has been carried out so far. We report herein preparation of eleven bipyri(mi) dinium salts 1-4 (Figure 1) and their further electrochemical studies. Three bipyridine isomers $\left(2,2^{\prime}, 3,3^{\prime}\right.$, and $\left.4,4^{\prime}\right)$ were examined and further structurally tuned by various bridges (ethylene or oxalyl), $\mathrm{N}$-substituents, and counter anions. Whereas 2,2'-bipyridines $1 \mathrm{a}-\mathrm{d}$ are zwitterionic, $1 \mathrm{e}-\mathrm{h}$ possess separate bromide or anthraquinonedisulfonate (AQDS) anions. $3,3^{\prime}$ - and 4,4'-bipyridine derivatives 2 and 3 are positional isomers of 1a, while bipyrimidine 4 relates to $1 \mathrm{e}$.

\section{RESULTS AND DISCUSSION}

\section{Synthesis}

The synthetic strategy toward bipyridines and their salts is outlined in Scheme 1. Starting materials 5, 6, 8, 9, and 10 are commercially available, while precursor 7 was prepared by oxidation of 1,10 phenantroline 6 using a mixture of sulfuric and nitric acids. Oneor two-fold $\mathrm{N}$-quaternization of 2,2'-bipyridines 5-7 with 1,3propanesultone in $\mathrm{N}, \mathrm{N}$-dimethylformamide (DMF) at $120^{\circ} \mathrm{C}$ afforded $1 \mathrm{a}-\mathrm{d}$ with the yields $10-75 \%$. Depending on the amount of the sultone used, parent $2,2^{\prime}$-bipyridine 5 can be quaternized on one (1b) or both (1a) nitrogen atoms. On the contrary, phenantroline derivatives 6 and 7 underwent only mono $\mathrm{N}$-alkylation, probably due to a steric hindrance. Repeated crystallization of phenanthroline derivative $1 \mathrm{~d}$ proved to be tedious and inefficient, therefore, $1 \mathrm{~d}$ can be prepared with only a limited purity ( $90 \%)$. The second series, consisting of ethylene bridged derivatives $1 \mathrm{e}-\mathrm{g}$ and 4 with bromide counter ions, was synthesized from 5-8 and 1,2-dibromoethane (used as solvent). The attained yields range from 35 to $96 \%$. The bromide anion in molecule 1e was further replaced by AQDS by its reaction with disodium 9,10-anthraquinone-2,6-disulfonate in toluene. Derivative $1 \mathrm{~h}$ was isolated in almost quantitative yield. The synthesis of bipyrimidinium derivative 4 was similar and provided moderate $44 \%$ yield. $3,3^{\prime}$ - and $4,4^{\prime}$-bipyridinium salts 2 and 3 were synthesized analogically to $1 \mathrm{a}$ by a two-fold

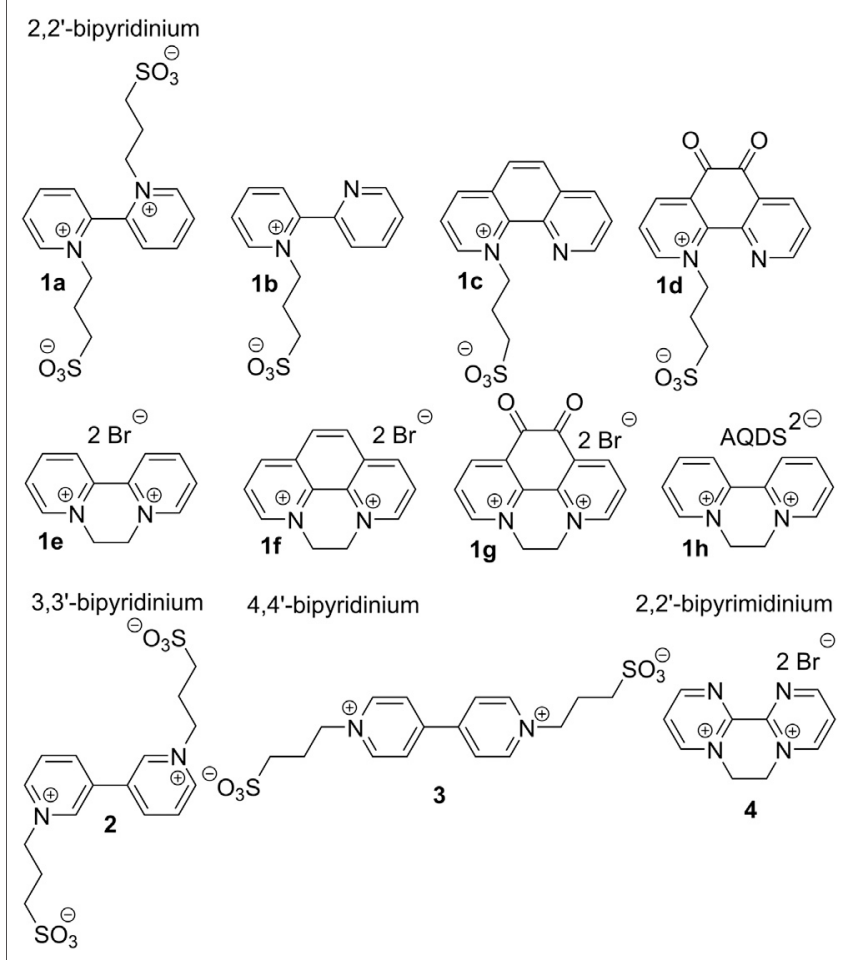

FIGURE 1 | Molecular structure of the synthesized bipyri(mi)diniums.

quaternization using 1,3-propanesultone in acetonitrile at $85^{\circ} \mathrm{C}$ with good yields 85 and $70 \%$, respectively. The synthesis, analytical data, and native spectra are given in the Supplementary Material.

\section{Electrochemical Characterization by Cyclic Voltammetry}

All target compounds were intended as anolytes for aqueous RFB and as such, they possess pyridinium and carbonyl redox centers. Electrochemical redox processes involving these centers were preliminarily screened by cyclic voltammetry carried out in

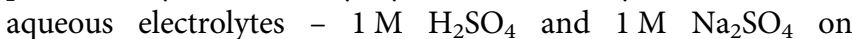
activated glassy carbon electrode (Bystron et al., 2019). Investigated bipyri(mi)dium salts $1-4$ proved to be unstable in alkaline media $(1 \mathrm{M} \mathrm{NaOH})$ as judged by their dark color and disappeared signals in ${ }^{1} \mathrm{H}$ NMR spectra (see the Supplementary Material). The fundamental electrochemical data are gathered in Supplementary Tables S1 and S2; a full list of measured voltammograms is given in the Supplementary Figures S2-7. All potentials within this study are related to a standard hydrogen electrode (SHE).

In neutral electrolyte $\left(\mathrm{Na}_{2} \mathrm{SO}_{4}\right)$, bipyridium 1a underwent two consecutive reductions (Figure $\mathbf{2 A}$ ), which reflects presence of two pyridinium units and increased electron density upon the first reduction (formation of an amine). A reduction of the residual impurity (1b) can be partially observed at $E_{\mathrm{pc1}}=$ $-0.97 \mathrm{~V}$. Indeed, this mono-quaternized derivative showed one reduction with the potential lying between the two aforementioned redox processes seen for 1a. In both media are 

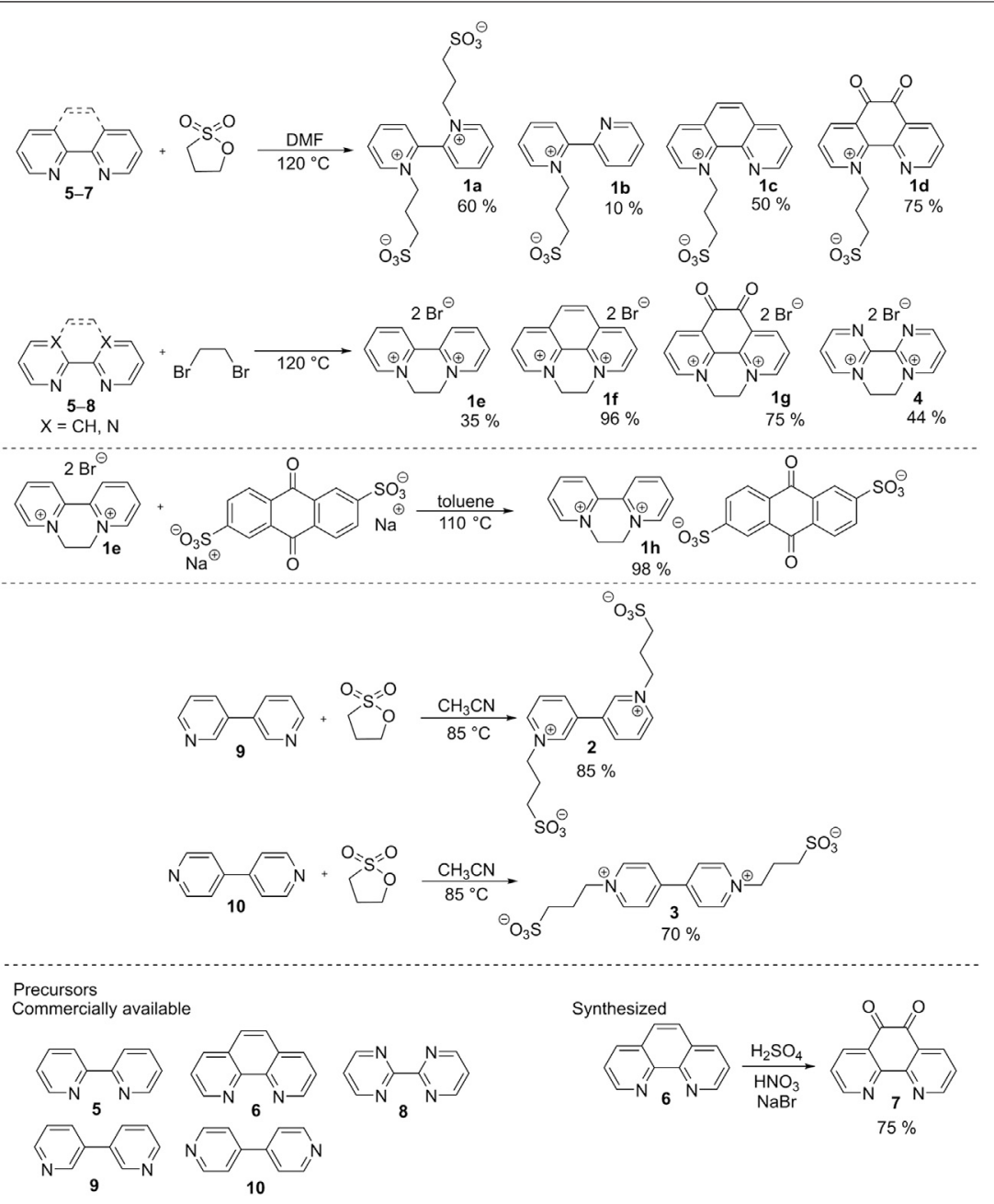

SCHEME 1 | The synthesis of target derivatives $1 a-h$ and $2-4$.

reductions of $1 \mathrm{a}-\mathrm{b}$ irreversible, which is probably due to subsequent chemical processes (dimerization) or possible protonation in acid media (and re-oxidation via a different pathway). A similar behavior was observed for phenanthroline derivative $1 c$, which is even less soluble in both electrolytes. Oxalyl-bridged compound 1d showed two consecutive electrochemical processes in neutral media that belong to oneelectron reduction of the pyridinium and the carbonyl group. Thus, the electron deficient pyridinium is reduced prior to the less polarized carbonyl function. Moreover, the re-oxidized species of $1 \mathrm{c}$ and $1 \mathrm{~d}$, generated at high overpotentials above $0 \mathrm{~V}$ vs. SHE, were strongly irreversible adsorbed at the electrode surface. This is probably due to a low solubility of $1 \mathrm{c}-\mathrm{d}$ containing only one solubilizing group. It is obvious that electrochemically generated reduced forms of 1a-d are chemically instable in both media. An extension and planarization of the $\pi$-system as well as introduction of the carbonyl redox center shift the reduction potential to more positive values. This is however undesirable for anolyte and do not bring a desired improvement in chemical stability of the reduced form(s).
From the recorded voltammograms we can further deduce that mono-quaternized bipyridines $1 \mathrm{~b}-\mathrm{d}$ are in acid media $(1 \mathrm{M}$ $\mathrm{H}_{2} \mathrm{SO}_{4}$ ) clearly protonated on the pyridine nitrogen. This results in a bipyridinium with permanent and temporary quaternization ( $\mathrm{N}$-alkylation/protonation) as demonstrated by a comparison of $1 \mathrm{a}$ and $1 \mathrm{~b}$ in acid and neutral media (Figure $\mathbf{2 B}$ ). Whereas the first reduction potential of $1 \mathrm{a}$ is $\mathrm{pH}$-independent, monoquaternized $1 \mathrm{~b}$ showed in acid media the first reduction potential shifted by $400 \mathrm{mV}$ to more positive value (see also Supplementary Tables S1 and S2). Derivative 1b underwent one-electron reduction in neutral media and two-electron reduction in $\mathrm{H}_{2} \mathrm{SO}_{4}$. The second electron transfer is carried out at the potential corresponding to the first reduction; the respective peak corresponds to a two-electron reduction process. This is due to immediate protonation of the amine generated upon the first reduction step, which keeps the scaffold electronically identical to a state before the first reduction. A similar behavior has been observed for all mono-quaternized derivatives $1 \mathrm{c}-\mathrm{d}$. For the same reason, bipyridinium 1a underwent in $1 \mathrm{M} \mathrm{H}_{2} \mathrm{SO}_{4}$ a single two-electron reduction. 

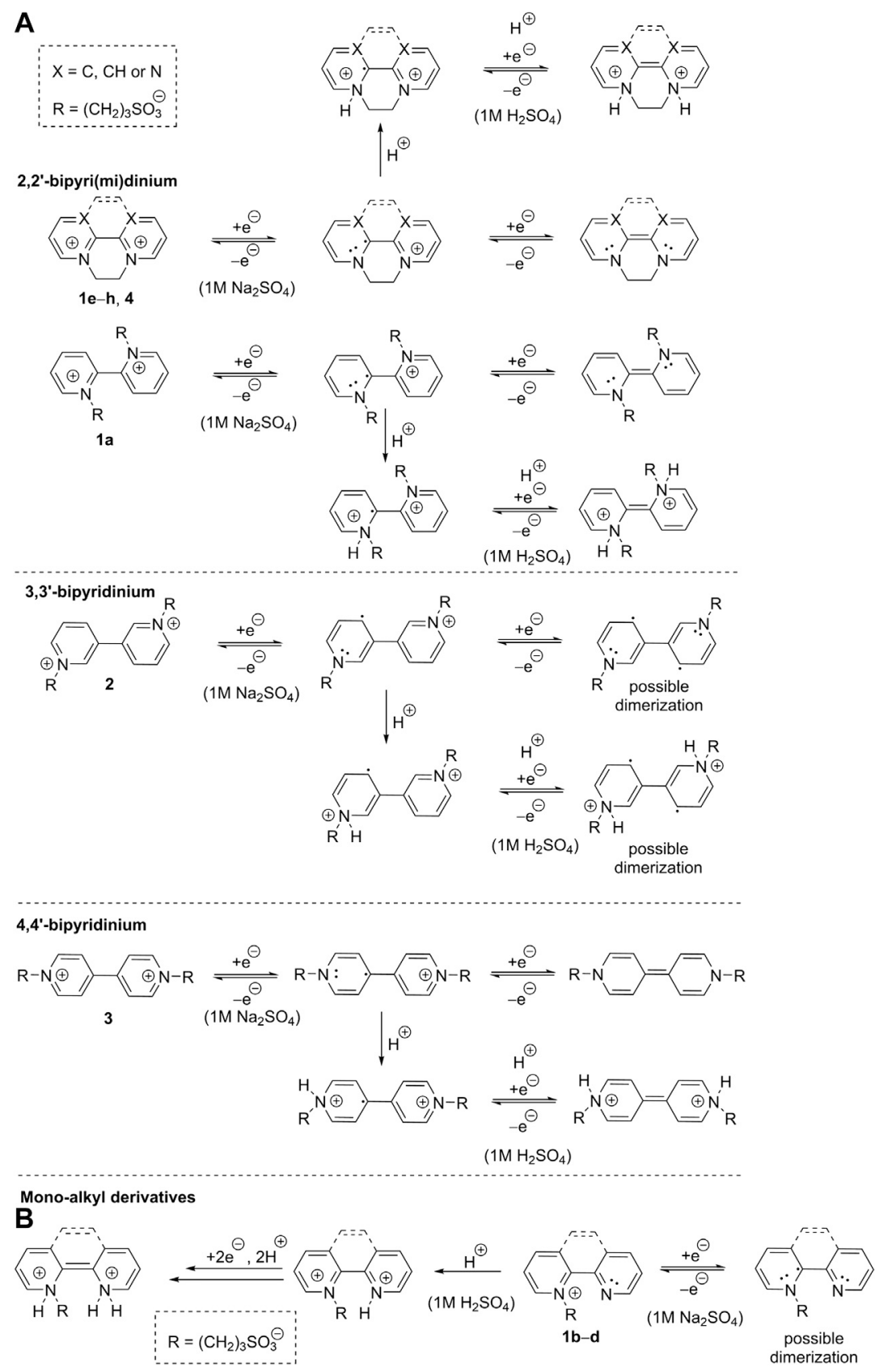

SCHEME 2 | Proposed two-electron reductions of bipyri(mi)diniums 1a, 1e-h, and 2-4 (A) and one- and two-electron reductions of pyridiniums salts 1b-d (B).

The second series of molecules 1e-g (Figure 3A) possesses an additional ethylene bridge, which assures their permanent quaternization. The counter ion is $\mathrm{Br}^{-}$with a quasi-reversible oxidation found at around $+1.3 \mathrm{~V}$. From the measured voltammograms is obvious that the reductions are almost independent on $\mathrm{pH}$ (Supplementary Tables S1 and S2). In both media, known diquat 1e underwent two consecutive oneelectron reductions; similarly to $1 \mathrm{l}$ are both processes merged in $1 \mathrm{M} \mathrm{H}_{2} \mathrm{SO}_{4}$ (Figure 3A and Supplementary Figure S4A). The first reduction is always reversible regardless of the used media, whereas the second process in acid media is irreversible as the fully reduced basic form (an amine) undergoes protonation and cannot be reoxidized over the same pathway. This protonation is suppressed in the neutral media, however, the fully reduced form is no more water-soluble and is being deposited on the electrode surface (a sharp peak of the re-oxidation). Despite is 1e capable to undergo two consecutive reversible reductions, its both redox centers are simultaneously solubilizing groups that are lost upon reduction. The water-insolubility of the fully reduced form limits its use as one-electron reducible RFB anolyte with lower volumetric energy capacity. Although interesting and reasonable, replacing bipyridinium scaffold with bipyrimidinium $(1 \mathrm{e} \rightarrow 4)$ turned out 


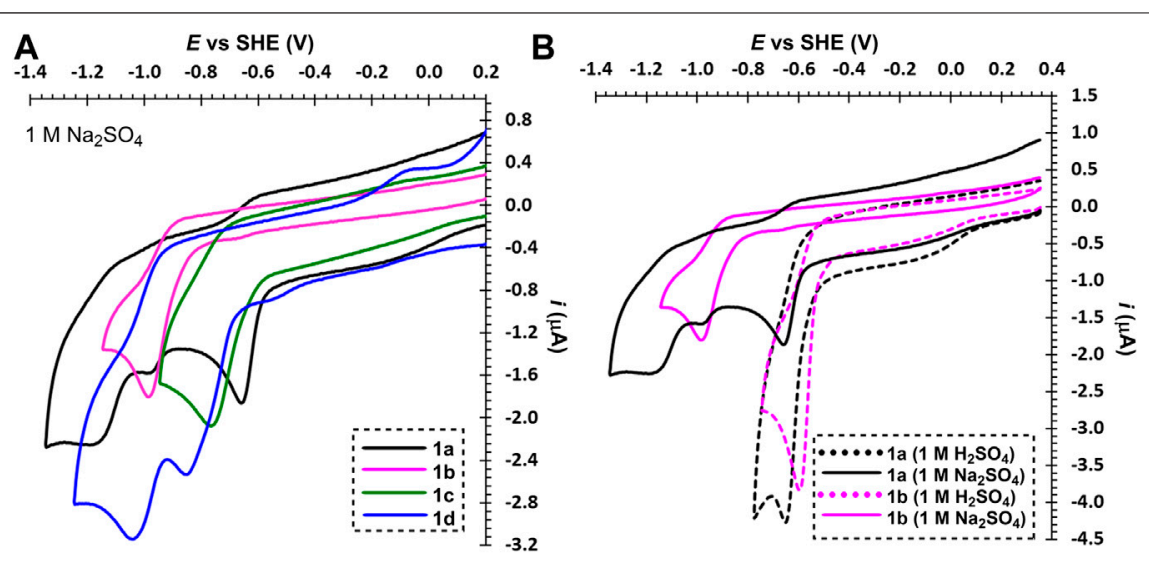

FIGURE 2 | Electrochemical reductions of 2,2'-bipyridiniums 1a-d (A) and 1a and 1b in neutral and acid media (B), $c \sim 1 \mathrm{mM}$.
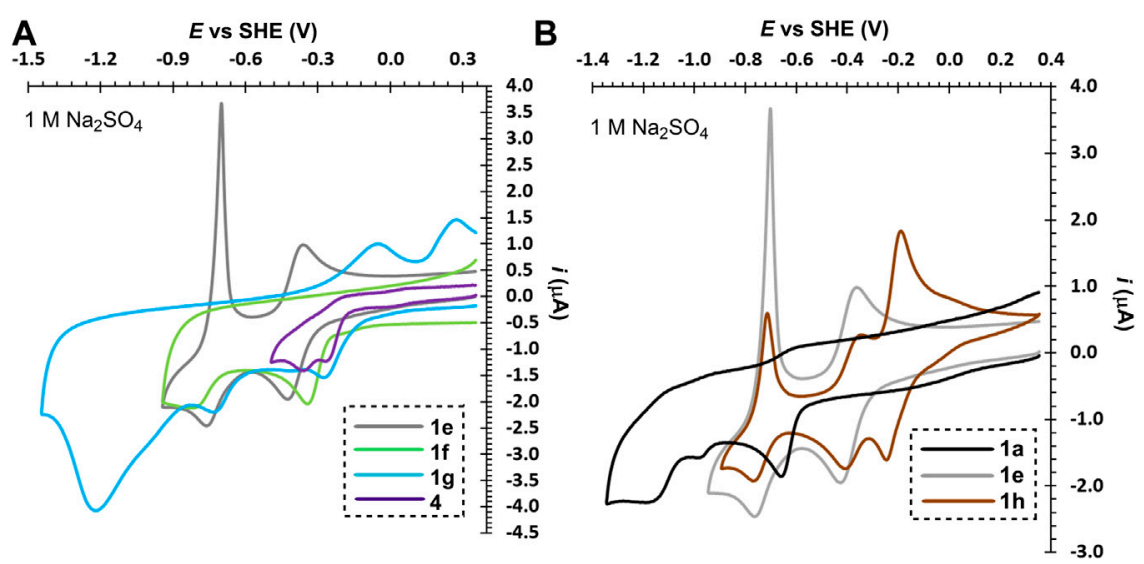

FIGURE 3 | Electrochemical reductions of bridged bipyridiniums 1a-g and 4 (A) and influence of the counter ion and planarity in bipyridiniums 1a, 1e, and 1h (B), $C \sim 1 \mathrm{mM}$.

to have very detrimental effect on the chemical stability of the reduced form (slightly more stable in acid media). Derivative 4 showed two following one-electron reductions and, as compared to $1 \mathrm{e}$, is more water-soluble. The electrochemical behavior of compounds if and $1 \mathrm{~g}$ is similar to those described for related derivatives $1 \mathrm{c}$ and $1 \mathrm{~d}$. Electrochemically reversible processes were in bipyridinium/bipyrimidinium series $1 \mathrm{e}-\mathrm{g} / 4$ observed solely for diquat $1 \mathrm{e}$ and its further structural tuning was rather counterproductive. Considering the whole series $1 \mathrm{a}-\mathrm{g}$ as well as compound 4 , the performed structural variation affected mostly chemical stability and solubility of the generated reduced forms.

Subsequently, we focused our attention toward the counter ion effect. The bromide ion in diquat 1e was replaced by AQDS, wellknown anolyte in RFB, to gain hybrid derivative $1 \mathrm{~h}$. The voltammograms in Figure 3B clearly show that beside the bipyridinium reduction, we observed also reversible reduction of the quinone system of AQDS. Whereas the position of the pyridinium reduction peaks is almost independent on $\mathrm{pH}$ (Supplementary Figure S1), the AQDS reduction is affected significantly as the AQDS redox processes involve either two or one proton(s) in acid/neutral media (Huskinson at al., 2014). A further comparison of rigid $1 \mathrm{e} / 1 \mathrm{~h}$ and nonplanar $1 \mathrm{a}$ reveals irreversible reduction of the latter. Hence, the planarity of the main $\pi$-conjugated scaffold as well as anti-arrangement of both nitrogen atoms seem to be significant parameters affecting electrochemical reversibility of $2,2^{\prime}$-bipyridines.

Figure 4 compares three particular bipyridinium salts that differ in mutual orientation of the rings (nitrogen atoms). Derivative 3, related to paraquat, showed two, reversible, one-electron reductions, which is in line with the published data (Liu et al., 2018). Its planar structure with remote alkyl chains preventing their repulsion allows efficient conjugation of both pyridinium rings. In contrast to $1 \mathrm{e}$ and due to two sulton residues, its fully reduced form is still soluble in water. Hence, in neutral media, both reduction steps can be utilized without a precipitation and deposition at the electrode surface. On the other hand, protonation of the fully reduced form in acid media prevents utilization of the second reduction step. When going from $4,4^{\prime}$ - to $2,2^{\prime}$ - and $3,3^{\prime}$-bypiridinium $(3 \rightarrow 1 \mathrm{a} \rightarrow 2)$, the first reduction potential shifts to more negative values. More 


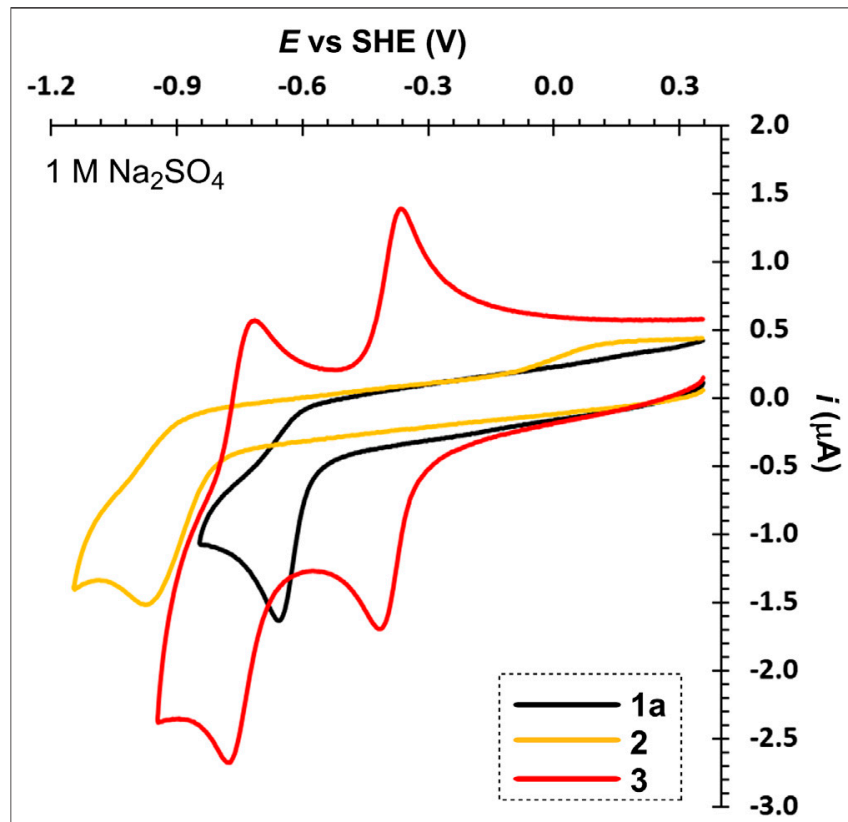

FIGURE 4 | A comparison of 2,2' - (1a), 3,3'- (2), and 4,4'-bipyridinium's (3) voltammograms, $c \sim 1 \mathrm{mM}$.

importantly, this shift is accompanied by a loss of reversibility. Both nitrogen atoms in 2 are localized out of alternating positions and, despite the lowest potential of the first reduction, the reduction product is chemically unstable and may undergo various consequent processes. On the contrary, both nitrogen atoms in 1a are alternating but proximity of two $\mathrm{C}=\mathrm{N}^{+}$polar bonds makes 1a prone to attack of hydroxide anion at basic conditions thus lowering its stability.

From the aforementioned electrochemical observations, we can propose a mechanism of two-electron reduction of bipyri(mi)diniums 1a, 1e-h, and 2-4 (Scheme 2A). In general, the first reduction of all derivatives generates radical cations with possible resonant stabilization, which partially suppress their dimerization. For 2,2'- and 4,4'-bipyridiniums, the second reduction affords quinoid arrangement, while this is not the case of $3,3^{\prime}$-bipyridinium. The latter possesses both nitrogen atoms in non-alternating positions and, therefore, its two-electron reduction produces diradical with diminished chemical stability. The reducible centers of $1 \mathrm{e}-\mathrm{h}$ and 4 are simultaneously solubilizing groups that are lost upon reduction. Hence, their two-electron reduction produces uncharged intermediates that are sparingly soluble in aqueous neutral media. On the contrary, derivatives 1a, 2, and 3 with sultone pendants are well soluble in water regardless their redox state. The (electro)chemical stability, the number of generated reduced forms, and the position of the redox potential are further influenced by the planarity, presence of the ethylene/oxalyl bridge, the number of $\mathrm{N}$-substituents, and the used media. Dialkyl derivatives 1a, $1 \mathrm{e}-\mathrm{h}$, and 2-4 are reduced in different way in acid media. Both reductions produce tertiary amines that are immediately protonated to afford ammonium salts (Scheme 2A). A mechanism of reduction of monoalkyl derivatives $1 \mathrm{~b}-\mathrm{d}$ is outlined in Scheme 2B. In neutral media, one-electron reduction takes place accompanied by a formation of unstable radical that may undergo further chemical processes. Pyridine ring of $1 \mathrm{~b}-\mathrm{d}$ is quickly protonated in acid media to afford dication and the subsequent two-electron reduction correspond to the aforementioned mechanism shown in Scheme 2A.

\section{Electrochemical Characterization on Rotating Disc Electrode (RDE)}

The selected compounds $1 \mathrm{e}$ and 3 exhibiting chemically reversible redox behavior in neutral environment were subsequently characterized on glassy carbon $\mathrm{RDE}$ in $1 \mathrm{M}$ $\mathrm{Na}_{2} \mathrm{SO}_{4}$; see the Supplementary Material for detailed description of the used methodology. The measured curves together with their evaluation are presented in Supplementary Figures S8-11. Levich and Koutecký-Levich analysis of the measurements revealed kinetic parameters and diffusion coefficients that are summarized in Supplementary Table S3. In accordance with the results of preliminary CV measurements described in the previous section both compounds exhibited two subsequent one electron quasi-reversible redox processes in a broad range of potential scan rates $\left(5,000-10 \mathrm{mV} \mathrm{s}^{-1}\right)$, see Supplementary Figure S8. The heterogeneous rate constant $k^{\circ}$ was evaluated from RDE measurement at various rotations (500-3,000 rpm) using Koutecky-Levich method. For the first redox step it was 7.9 and $15.1 \times 10^{-3} \mathrm{~cm} \mathrm{~s}^{-1}$ for $1 \mathrm{e}$ and 3 , respectively. In case of 3 the obtained value is significantly lower than the reported values for the identical compound in neutral electrolyte $\left(0.28 \mathrm{~cm} \mathrm{~s}^{-1}\right)$ (DeBruler et al., 2018). The discrepancy between the values is most probably caused by inaccuracy of Nicholson method, which was used for the estimation of $k^{\circ}$ in the cited study. Nevertheless, the value of $k^{\circ}$ are still by orders of magnitude higher than in case of mostly exploited vanadium redox couples $\left(1.7 \times 10^{-5} \mathrm{~cm} \mathrm{~s}^{-1}\right.$ for $\mathrm{V}^{3+} / \mathrm{V}^{2+}$ in acidic electrolyte) (Sum and Skyllas-Kazacos, 1985). The fast electrode reaction kinetics of the bipyridine-based molecules is promising for their application in redox flow battery, in particular, with respect to low activation polarization of the battery. The diffusion coefficient evaluated from the same RDE measurements were 2.9 and $2.5 \times 10^{-6} \mathrm{~cm}^{2} \mathrm{~s}^{-1}$ for $1 \mathrm{e}$ and 3 , respectively. These results indicate that the difference in structure of both molecules does not cause big differences in their diffusivities. For compound 3 the achieved value is fully in line with the previously reported values (DeBruler et al., 2018). The high values of $D$ are required for the efficient battery operation at high current densities, where the efficiency losses of the battery related to mass transport of active species (reactants) to the electrode surface are dominating.

\section{Electrochemical Stability in Flow Battery Half-Cell}

The compounds $1 \mathrm{e}$ and 3 exhibiting quasi-reversible electrochemical behavior on glassy carbon were subsequently 
TABLE 1 | Parameters evaluated from the galvanostatic cycling of electrolytes in flow electrolysis cell.



aMaximal discharge (oxidation) capacity obtained during cycling.

${ }^{b}$ Averaged value from the 10th-20th cycle.

${ }^{c}$ Evaluated from slope of capacity-cycle number dependence from the 10th-50th cycle.

${ }^{d}$ Evaluated from difference between capacity of the 1 st and 50 th cycle.
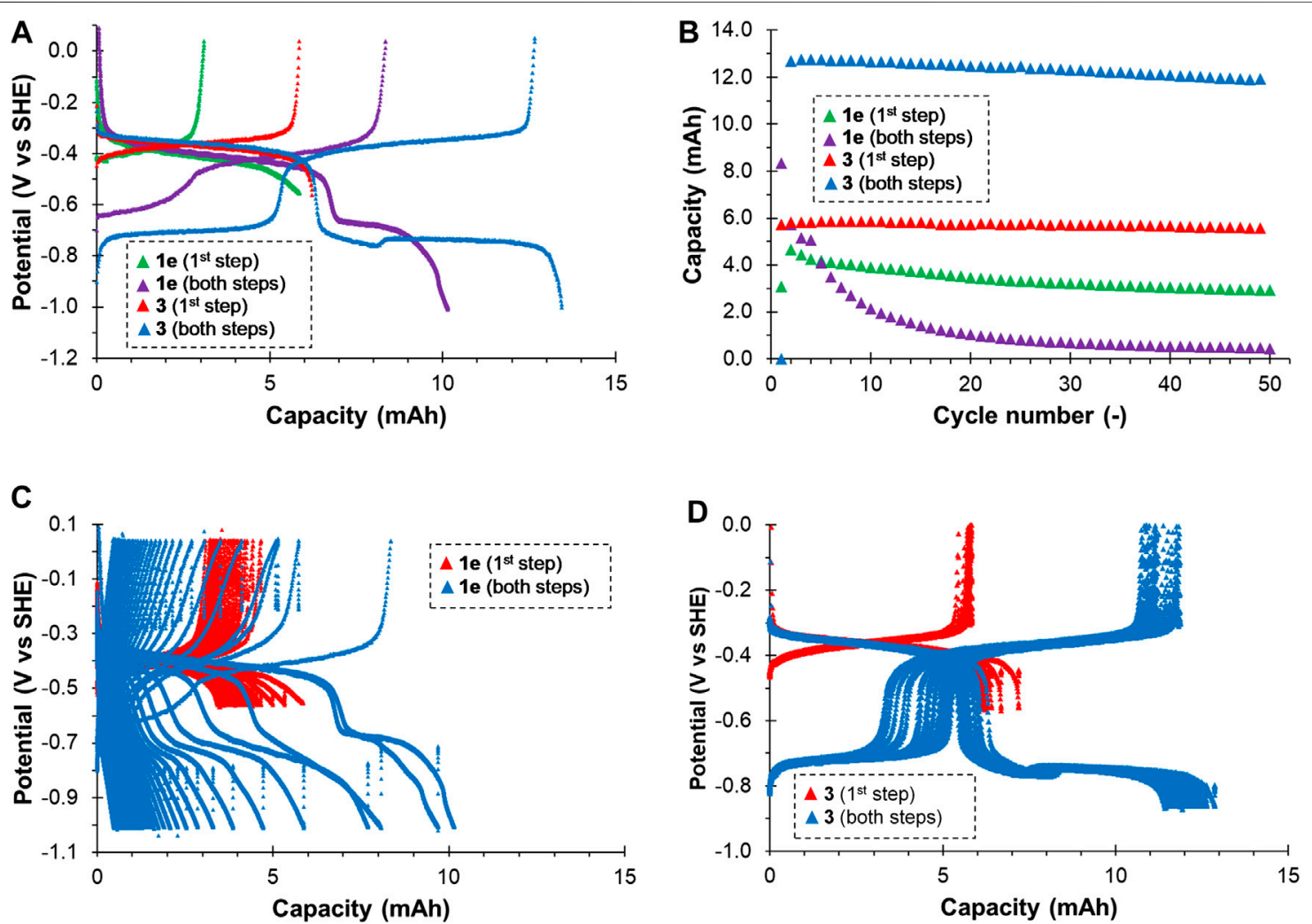

FIGURE 5 | Galvanostatic reduction-oxidation cycling of neutral electrolyte based on bipyridiniums $1 \mathrm{e}$ and 3 at $12.5 \mathrm{~mA} \mathrm{~cm}^{-2}, 20^{\circ} \mathrm{C}$ : Development of working electrode potential of electrolysis cell during the first cycle (A); Evolution of oxidation (discharge) capacity during entire cycling (B); Development of working electrode potential of electrolysis cell during entire cycling for $1 \mathrm{e}$ (C) and 3 (D)

tested in a flow battery cell in 3-electrode set-up using thermally treated graphite felt working electrode. The $25 \mathrm{mM}$ solution of the active compound in neutral supporting electrolyte was galvanostatically cycled in a potential window corresponding to the first and both redox steps, while hydrogen and oxygen evolution from the supporting electrolyte proceeded on a counter electrode separated from the working electrode by an ionexchange membrane preventing cross-over of active compound through the membrane. We used anion-exchange membrane for cationic 1e, while for zwitterionic 3, high equivalent weight cation-exchange membrane was employed. Negligible permeation of both active compounds was confirmed by UV-Vis analysis of counter electrolyte after the cycling. Moderate current density of $12.5 \mathrm{~mA} \mathrm{~cm}^{-2}$ and relatively high electrolyte flow rate of $40 \mathrm{ml} \mathrm{min}^{-1}$ were used to minimize mass transport polarization of the working electrode. The parameters evaluated from the battery cycling of both compounds are summarized in Table 1. The reductionoxidation potential profile is shown in Figure 5. For both compounds we can see two reduction and oxidation plateaus corresponding to the first (at approx. $-0.4 \mathrm{~V}$ vs. SHE) and second step (at approx. $-0.7 \mathrm{~V}$ vs. SHE), which agrees well with the aforementioned $\mathrm{CV}$ measurements on glassy carbon. However, both compounds behaved differently in terms of capacity 
utilization $(C U)$, Coulombic efficiency $(C E)$, and stability upon cycling. In case of 1e we observed relatively low values of $C U$ and $C E$ and fast capacity decay $\left(2.5 \% Q_{\text {theo }} /\right.$ cycle leading to almost $60 \%$ capacity loss within 50 cycles) when cycled within both redox steps. This decay was most probably caused by deposition of the fully reduced (and thus non-ionic) 1e on the surface of graphite felt electrode, which has formerly been reported for similar derivatives (Bird and Kuhn, 1981). Smaller capacity decay was observed for cycling in the first redox step region $(0.7 \%$ $Q_{\text {theo. }} /$ cycle leading to $26 \%$ capacity loss within 50 cycles). As reported for bipyridine-based compounds (Bird and Kuhn, 1981), this can be attributed to dimerization, chemical reaction or disproportionation of partially reduced bipyridine radical leading to deposition of insoluble fully reduced form.

On the contrary, compound 3 showed significantly better performance and stability in both potential ranges. Very small capacity decay of $0.09 \% Q_{\text {theo. }} /$ cycle leading to $4.2 \%$ overall capacity decay after 50 cycles was observed for the first reduction step. Slightly higher decay was observed when cycled in both reduction steps: $0.15 \% Q_{\text {theo. }} /$ cycle leading to over $6 \%$ loss of the theoretical capacity within 50 cycles.

\section{NMR Post Mortem Analysis}

The redox processes of $1 \mathrm{e}$ and 3 were also monitored by ${ }^{1} \mathrm{H}$ nuclear magnetic resonance (NMR), see the Supplementary Material for detailed description. The NMR post mortem analysis of bipyridinium 1e after cycling in the battery half-cell showed significant decrease of the signals corresponding to initial compound when cycled within the first step (around 70\% loss of material, Supplementary Figure S12, Spectrum 2) and complete loss of the initial compound when cycled in both steps (Supplementary Figure S12, Spectrum 3). Detailed inspection of the ${ }^{1} \mathrm{H}$ NMR Spectrum 3 revealed the presence of ca. $20 \%$ of broad signals, hinting formation of insoluble polymeric materials. Attempted extraction of the organic material from the electrode with DMSO gave no results. Hence, polymeric water-insoluble compounds were probably formed under the experimental conditions. Analogous post mortem ${ }^{1} \mathrm{H}$ NMR spectroscopy analysis of 3 showed around $18 \%$ loss of the starting compound 3 after 50 cycles at the first step (Supplementary Figure S13, Spectrum 2) and surprising complete disappearance of signals after cycling in both steps (Supplementary Figure S13, Spectrum 4). This is in contrast with observed electrochemical data showing negligible capacity fade of the battery and can be explained by analyzing $\mathrm{pH}$ of the mixtures. We found that both samples were quite basic ( $\mathrm{pH} \sim 12)$, which is due to formation of an amine upon both reduction steps (see Scheme 2). A solution of structurally related piperidine in aqueous $\mathrm{Na}_{2} \mathrm{SO}_{4}$ of similar concentration possesses $\mathrm{pH}$ 12.3. Under such alkaline condition, we assumed that reversible reaction of 3 with hydroxide anion is responsible for blurring the NMR signals (see Supplementary Material for extended discussion). Indeed, mild acidification of the mixtures with $\mathrm{NaH}_{2} \mathrm{PO}_{4}$ led to reappearing of the NMR signals. When the electrochemical experiments were performed in the presence $0.1 \mathrm{M} \mathrm{Na}_{2} \mathrm{HPO}_{4} /$ $\mathrm{NaH}_{2} \mathrm{PO}_{4}$ buffer, no blurring of the signals was observed. However, we observed about $20 \%$ loss of the starting compound 3, probably due to decomposition under basic condition (see Supplementary Figure S13, Spectra 3 and 5).

\section{CONCLUSION}

A series of bipyri(mi)dinium derivatives with systematically evaluated structure has been designed and synthesized. These represent a popular class of salts applicable in aqueous redox flow batteries. Based on the aforementioned discussion, the following outcomes and structure-property relationships can be summarized/elucidated:

- The straightforward synthesis involves $N$-alkylation; the reaction with 1,3-propanesultone seems to be the most useful strategy.

- The fundamental electrochemical properties of bipyri(mi) dinium salts is affected by the number of quaternized nitrogens (one- or two-step(s) reduction). Due to anticipated higher capacity, two pyridinium centers are preferred for application in RFB.

- Bipyridinium regioisomers with different mutual orientation of the nitrogen atoms $\left(2,2^{\prime}, 3,3^{\prime}\right.$, and $\left.4,4^{\prime}\right)$ affect mostly the reversibility of the redox processes (repulsion of $N$-alkyl groups and non-conjugate arrangement). 4,4'-Bipyridine is preferred as a parent scaffold.

- 3-Sulfonatopropyl proved to be excellent solubilizing group as it brings permanent water solubility regardless the redox state of the used bipyridinium. Two $N$-alkyls are generally preferred.

- Further bridges such as oxalyl, ethylene or ethenylene planarizes the p-system but shift the reduction potential to more positive values and do not improve stability of the reduced form.

- The counter ion must also be considered, as bromide is electrochemically active but may be easily replaced with AQDS, which brings additional redox centers. Zwitterionic arrangement, as present in sultone derivatives, is preferred.

- The used media is another important aspect. Whereas bipyri(mi)dinium salts proved to be unstable in alkaline media, neutral or acid media significantly affect reversibility of the redox process (possible protonation of the intermediate amines).

- Detailed electrochemical characterization of compounds 1e and 3 on glassy carbon rotation disc electrode revealed fast reaction kinetics of both compounds and comparable values of diffusion coefficient.

- Investigation of compounds $1 \mathrm{e}$ and 3 in flow battery halfcell revealed much better electrochemical stability and Coulombic efficiency upon galvanostatic cycling of the latter. It features a trade-off between all desired structural aspects listed above.

- The performed NMR post mortem analysis corroborates the electrochemical outcomes and revealed significant electrolyte alkalization accompanied by a loss of material. 
This is due to formation of an amine upon the first and the second reduction. This obstacle may be partially suppressed by buffering the solution.

\section{DATA AVAILABILITY STATEMENT}

The original contributions presented in the study are included in the article/Supplementary Material, further inquiries can be directed to the corresponding authors.

\section{AUTHOR CONTRIBUTIONS}

ZB carried out the synthetic part of the work, MK performed the $\mathrm{CV}$ experiments, $\mathrm{PM}$ and MM investigated the target compounds by RDE and performed the battery cell studies, TB cooperated on analysis and evaluation of electrochemical experiment, JK carried

\section{REFERENCES}

Alesanco, Y., Viñuales, A., Palenzuela, J., Odriozola, I., Cabañero, G., Rodriguez, J., et al. (2016). Multicolor electrochromics: rainbow-like devices. ACS Appl. Mater. Interfaces 8, 14795-14801. doi:10.1021/acsami.6b01911

Beh, E. S., de Porcellins, D., Garcia, R. L., Xia, K. T., Gordon, R. G., and Aziz, M. J. (2017). A neutral $\mathrm{pH}$ aqueous organic-organometallic redox flow battery with extremely high capacity retention. ACS Energy Lett. 2, 639-644. doi:10.1021/ acsenergylett.7b00019

Bird, C. L., and Kuhn, A. T. (1981). Electrochemistry of the viologens. Chem. Soc. Rev. 10 (1), 49-82. doi:10.1039/CS9811000049

Bystron, T., Sramkova, E., Dvorak, F., and Bouzek, K. (2019). Glassy carbon electrode activation - a way towards highly active, reproducible and stable electrode surface. Electrochim. Acta 299, 963-970. doi:10.1016/j.electacta.2019.01.066

Coumans, R. G., Elemans, J. A., Rowan, A. E., and Nolte, R. J. (2013). Interlocked porphyrin switches. Chemistry 19, 7758-7770. doi:10.1002/ chem. 201203983

DeBruler, C., Hu, B., Moss, J., Liu, X., Luo, J., Sun, Y., et al. (2017). Designer two-electron storage viologen anolyte materials for neutral aqueous organic redox flow batteries. Inside Chem. 3 (6), 961-978. doi:10.1016/j. chempr.2017.11.001

DeBruler, C., Hu, B., Moss, J., Luo, J., and Liu, T. L. (2018). A sulfonatefunctionalized viologen enabling neutral cation exchange, aqueous organic redox flow batteries toward renewable energy storage. ACS Energy Lett. 3 (3), 663-668. doi:10.1021/acsenergylett.7b01302

Gray, M. R., Tan, X., and Fenniri, H. (2008). Pyrene derivatives of 2,2'-bipyridine as models for asphaltenes: synthesis, characterization, and supramolecular organization. Energy Fuels 22, 715-720. doi:10.1021/ef700395g

$\mathrm{Hu}$, B., DeBruler, C., Rhodes, Z., and Liu, T. L. (2017). Long-cycling aqueous organic redox flow battery (AORFB) toward sustainable and safe energy storage. J. Am. Chem. Soc. 139, 1207-1214. doi:10.1021/jacs.6b10984

Hu, B., Tang, Y., Luo, J., Grove, G., Guo, Y., and Liu, T. L. (2018). Improved radical stability of viologen anolytes in aqueous organic redox flow batteries. Chem. Commun. 54 (50), 6871-6874. doi:10.1039/c8cc02336k

Huskinson, B., Marshak, M. P., Suh, C., Er, S., Gerhardt, M. R., Galvin, C. J., et al. (2014). A metal-free organic-inorganic aqueous flow battery. Nature 505, 195-198. doi:10.1038/nature12909

Janoschka, T., Martin, N., Hager, M. D., and Schubert, U. S. (2016). An aqueous redox-flow battery with high capacity and power: the TEMPTMA/MV system. Angew Chem. Int. Ed. Engl. 55, 14427-14430. doi:10.1002/anie. 201606472

Janoschka, T., Martin, N., Martin, U., Friebe, C., Morgenstern, S., Hiller, H., et al. (2015). An aqueous, polymer-based redox-flow battery using non- out the NMR experiments, $\mathrm{ZB}, \mathrm{FB}, \mathrm{MK}$, and PM wrote the manuscript. All authors contributed to the article and approved the submitted version.

\section{FUNDING}

The work has been supported from European Regional development Fund-Project "Organic redox couple based batteries for energetics of traditional and renewable resources (ORGBAT)”, No. CZ.02.1.01/0.0/0.0/16_025/0007445.

\section{SUPPLEMENTARY MATERIAL}

The Supplementary Material for this article can be found online at: https:/www.frontiersin.org/articles/10.3389/fchem.2020.631477/ full\#supplementary-material.

corrosive, safe, and low-cost materials. Nature 527, 78-81. doi:10.1038/ nature 15746

Jin, S., Fell, E. M., Vina-Lopez, L., Jing, Y., Michalak, P. W., Gordon, R. G., et al. (2020). Near neutral $\mathrm{pH}$ redox flow battery with low permeability and longlifetime phosphonated viologen active species. Adv. Energy Mater. 10 (20), 2000100. doi:10.1002/aenm.202000100

Kallianos, A. G., Warfield, A. H., and Galloway, W. D. (1972). Some new alkaloids from burley tobacco. Phytochemistry 11, 3371-3375. doi:10.1016/S0031-9422(00)86411-0

Liu, T., Hu, B., DeBruler, C., and Luo, J. (2018). Materials for use in an aqueous organic redox flow battery. Utah State University. US20180072669 A1.

Liu, T., Wei, X., Nie, Z., Sprenkle, V., and Wang, W. (2016). A total organic aqueous redox flow battery employing a low cost and sustainable methyl viologen anolyte and 4-HO-TEMPO catholyte. Adv. Energy Mater. 6, 1501449. doi:10.1002/aenm.201501449

Liu, Y., Li, Y., Zuo, P., Chen, Q., Tang, G., Sun, P., et al. (2020). Screening viologen derivatives for neutral aqueous organic redox flow batteries. ChemSusChem 13 (9), 2245-2249. doi:10.1002/cssc.202000381

Monk, P. M. S., Turner, C., and Akhtar, S. P. (1999). Electrochemical behaviour of methyl viologen in a matrix of paper. Electrochim. Acta 44, 4817-4826. doi:10. 1016/S0013-4686(99)00225-X

Ohira, A., Funaki, T., Ishida, E., Kim, J.-D., and Sato, Y. (2020). Redox-flow battery operating in neutral and acidic environments with multielectron-transfer-type viologen molecular assembly. ACS Appl. Energy Mater. 3 (5), 4377-4383. doi:10.1021/acsaem.0c00067

Song, Y., Huang, X., Hua, H., and Wang, Q. (2017). The synthesis of a rigid conjugated viologen and its cucurbituril pseudorotaxanes. Dyes Pigments 137, 229-235. doi:10.1016/j.dyepig.2016.10.012

Sum, E., and Skyllas-Kazacos, M. (1985). A study of the V(II)/V(III) redox couple for redox flow cell applications. J. Power Sources 15 (2-3), 179-190. doi:10. 1016/0378-7753(85)80071-9

Summers, L. A. (1984). The bipyridines. Adv. Heterocycl. Chem. 35, 281-374. doi:10.1016/S0065-2725(08)60151-8

Conflict of Interest: The authors declare that the research was conducted in the absence of any commercial or financial relationships that could be construed as a potential conflict of interest.

Copyright (C) 2021 Burešová, Klikar, Mazúr, Mikešová, Kvíčala, Bystron and Bureš This is an open-access article distributed under the terms of the Creative Commons Attribution License (CC BY). The use, distribution or reproduction in other forums is permitted, provided the original author(s) and the copyright owner(s) are credited and that the original publication in this journal is cited, in accordance with accepted academic practice. No use, distribution or reproduction is permitted which does not comply with these terms. 